\title{
COVID - 19: MEDIDAS DE PREVENÇÃO DE LESÃO POR PRESSÃO OCASIONADAS POR EQUIPAMENTOS DE PROTEÇÃO INDIVIDUAL EM PROFISSIONAIS DA SAÚDE
}

\section{COVID - 19: PRESSURE INJURY PREVENTION MEASURES OCCURRED BY INDIVIDUAL PROTECTION EQUIPMENT IN HEALTH PROFESSIONALS}

\author{
Alessandra Rocha Luz ${ }^{1 *}$ Rogério Mendonça de Noronha ${ }^{2 *}$ Túlio Pinho Navarro ${ }^{3}$
}

\begin{abstract}
RESUMO
Diante da pandemia de COVID-19 se fez necessários várias medidas preventivas para evitar a contaminação pela doença e para evitar outros acometimentos aos pacientes e profissionais. A Organização Mundial de Saúde preconiza, o isolamento social e/ou afastamento, higienização das mãos, o uso de máscaras para pacientes com suspeitas de COVID-19, de forma empírica, o uso de máscaras de tecido para população fora do domicílio e reafirma a necessidade do uso da máscara N-95 e demais equipamentos individuais de proteção para os profissionais de saúde para evitar contaminação pelo coronavírus. Frente a essa pandemia, o uso contínuo de EPI's pelos profissionais de saúde durante todo o seu horário de trabalho, aumenta o risco para desenvolver lesões, há poucos relatos na literatura. Objetivo: identificar na literatura, as medidas preventivas para desenvolver lesão por pressão em profissionais de saúde. Métodos: revisão integrativa, estudos publicados entre os anos de 2000 a 2020. Resultados: Foram selecionados 14 artigos, diferentes delineamentos de pesquisa. Verificouse maior parte das publicações da China. As principais recomendações descritas foram os cuidados com a pele, como hidratação e aplicação de produtos protetores que permitam a vedação do equipamento de proteção individual. Considerações finais: Não há estudos suficientes, até o momento, que permitam elencar medidas que de fato venham a proteger o profissional a desenvolver lesões devido ao uso de equipamentos de proteção, são recomendadas medidas com base nos protocolos voltados para os pacientes em uso de ventilação não invasiva, baseados nas mesmas forças mecânicas (pressão e cisalhamento).
\end{abstract}

Palavras-chave: Lesão por Pressão; Infecções por Coronavírus; Equipamento de Proteção Individual; Profissional da Saúde; Vírus da SARS.

\begin{abstract}
In the face of the COVID-19 pandemic, several preventive measures were necessary to avoid contamination by the disease and to avoid other attacks on patients and professionals. The World Health Organization recommends, social isolation and / or removal, hand hygiene, the use of masks for patients with suspected COVID-19, empirically, the use of fabric masks for people outside the home and reaffirms the need for the use of the N-95 mask and other individual protective equipment for health professionals to avoid contamination by the coronavirus. Faced with this pandemic, the continuous use of PPE's by health professionals throughout their working hours increases the risk of developing injuries, there are few reports in the literature. Objective: to identify in the literature, preventive measures to develop pressure injuries in health professionals. Methods: integrative review, studies published between 2000 and 2020. Results: 14 articles were selected, with different research designs. Most of the publications from China were found. The main recommendations described were skin care, such as hydration and application of protective products that allow the sealing of personal protective equipment. Final considerations: There are not enough studies, so far, to list measures that will actually protect the professional from developing injuries due to the use of protective equipment, measures based on protocols for patients using ventilation are recommended. non-invasive, based on the same mechanical forces (pressure and shear).
\end{abstract}

Keywords: Pressure Ulcer; Coronavirus Infections; Personal Protective Equipment; Health personnel; SARS Virus.

\footnotetext{
${ }^{1}$ Enfermeira. Especialista em Dermatologia. Coordenadora da Comissão de Prevenção e Tratamento de Feridas do Hospital Risoleta Tolentino Neves. Mestre em Cirurgia pela Universidade Federal de Minas Gerais. ${ }^{2}$ Médico. Cirurgião Plástico pela Universidade Federal de Minas Gerais. Membro da Comissão de Prevenção e Tratamento de Feridas do Hospital Risoleta Tolentino Neves. Coordenador do Centro de Tratamento de Feridas e Medicina Hiperbárica do Hospital Santa Rita. ${ }^{3}$ Médico. Docente do Departamento de Cirurgia da Universidade Federal de Minas Gerais. Coordenador do Serviço de Cirurgia Vascular da Universidade Federal de Minas Gerais (Hospital Risoleta Tolentino Neves e Hospital das Clínicas). Belo Horizonte - Minas Gerais, Brasil. E-mail: alessandrarochaluz@ gmail.com.
} 


\section{INTRODUÇÃO}

Em dezembro de 2019, o mundo viu surgir uma pneumonia de causa, até então desconhecida, de origem na cidade de Wuhan/China, reportando o surto para Organização Mundial de Saúde. Um mês depois foi declarado epidemia, posteriormente uma pandemia. Após cerca de 40 dias do surgimento, foi possível divulgar a causa, sendo infecção por um novo vírus do coronavírus SARS-Cov-2. Esta ameaça mundial, ficou conhecida como doença coronavírus (COVID19) ${ }^{(1)}$.

Considerando a data de 14 de junho de 2020, os dados estatísticos apresentados em tempo real (Worldometers 2020) $^{(2)}$ são 7.984.307 de casos confirmados e 435.176 óbitos no mundo, no Brasil, considerando o mesmo período, foram 867.882 casos confirmados e 43.389 óbitos ${ }^{(2)}$.

Sua transmissão ocorre por vias aéreas, com alta transmissibilidade, com contato direto após tocar em superfícies contaminas e tocar na boca, nariz ou olhos, ou então através da liberação de gotículas contendo vírus de uma pessoa infectada ${ }^{(3)}$. O diagnóstico inicial é clínico a partir da avaliação médica dos sintomas, histórico de contato próximo ou domiciliar, sendo confirmado com exames laboratoriais (RT - PCR) ou teste rápido.

Diante de tal fato se faz necessário medidas preventivas, assim, a Organização Mundial de Saúde preconiza, de forma geral, como medidas para reduzir o número de casos de COVID-19, o isolamento social e/ou afastamento por mínimo de um metro entre pessoas em meio social e comércio, higienização das mãos com frequência com água e sabão, e quando não for possível lavar as mãos ou não possuir sujidade aparente, realizar higienização com álcool em gel. O uso de máscaras tem sido recomendado durante a assistência a pacientes com suspeitas de COVID-9 e de forma empírica, o uso de máscaras de tecido pela população fora do domicílio $^{(1)}$.

Para os profissionais de saúde as medidas preventivas, são baseadas no uso de equipamentos de proteção individuais (EPI's), entre eles o uso de máscara, óculos de proteção e protetor facial, capote impermeável de mangas longas, luvas, higienização das mãos com frequência, não tocar na face com mão enluvadas, atentar para os cuidados durante o transporte de pacientes, sempre portando os EPI's corretamente, entre outras medidas.

Frente a essa pandemia, identificamos na mídia e no dia-a-dia dos hospitais, fotos de profissionais com alterações na pele devido uso 
contínuo de EPI's durante longa jornada de trabalho, tal fato tem chamado atenção, por serem lesões por pressão relacionadas a dispositivos médico, o que até o momento, não há estudos com boa evidência na literatura, visto que, o profissional utiliza esses equipamentos apenas em momentos em que está diretamente na assistência para determinados cuidados ao paciente, representando alguns minutos, e posteriormente esses equipamentos são retirados. Porém, diante da pandemia por COVID-19, o momento de desparamentação tem sido o momento de maior risco para o profissional se contaminar, assim, a retirada dos EPI's tem sido postergado, de 4 a 8 horas com uso direto dos equipamentos, principalmente máscara N95 ${ }^{(4)}$. Durante esse período de pandemia, um estudo foi realizado por Jiang ${ }^{(5)}$ e identificou que $42,8 \%$ dos profissionais apresentavam lesões de pele devido ao uso prolongado dos EPI, sendo três tipos de lesões: lesão por pressão relacionada a dispositivos médicos, danos à pele associada a umidade e a lacrimejamento.

As lesões por pressão são consideradas indicadores de qualidade da assistência nos serviços de saúde. Tem surgido, já algum tempo, movimentos para conscientização quanto às medidas preventivas, devido aos programas de segurança do paciente e a partir da elaboração e execução de protocolos ${ }^{(6)}$.
Anteriormente denominada úlcera por pressão, porém devido ao conceito de úlcera ser ruptura da pele e a classificação estágio 1 não haver ruptura da pele, mas considerada lesão na pele, optou-se por utilizar o termo lesão por pressão (LPP) ${ }^{(7)}$. Além da mudança na denominação, a NPIAP tem abordado novas classificações, como a lesão por pressão relacionada a dispositivos médicos ${ }^{(8)}$.

Estas lesões em profissionais ocorrem devido às mesmas forças mecânicas (pressão e cisalhamento) que causam lesões por pressão em nossos pacientes, porém, no caso dos profissionais a origem são os equipamentos de proteção individual. As máscaras N95 têm um risco particularmente alto de ferimentos devido aos requisitos para um ajuste apertado ${ }^{(9)}$.

Considerando o importante papel do profissional de saúde diante da pandemia de COVID-19, questiona-se: quais são as medidas preventivas para lesão por pressão relacionada a dispositivos médico em profissionais?

\section{OBJETIVOS}

Assim este estudo tem como objetivo identificar na literatura, as medidas preventivas para desenvolver lesão por pressão relacionada a dispositivos médicos voltadas para os profissionais de saúde com uso de equipamentos de proteção individual. 


\section{METODOS}

Realizou-se uma revisão integrativa, incluindo estudos com diferentes abordagens metodológicas, no recorte temporal de 2000 a 2020 para contemplar um intervalo de tempo que permitisse a inclusão de mais estudos, considerando outras situações de surto ou pandemias.

Seleção do estudo

Para a construção deste, foram seguidas as seguintes etapas: 1) Delimitação do tema e definição da pergunta; 2) Estabelecimento dos critérios de inclusão e exclusão/ amostragem dos estudos; 4) Avaliação dos estudos incluídos na revisão; 5) Discussão dos resultados da amostra trabalhada e; 6) Apresentação da síntese do conhecimento.

Para extração de informações foram consultadas publicações indexadas nas bases de dados eletrônicas pelo portal PUBMED (Base de Dados Bibliográficas em Medicina), Base de dados em Enfermagem (BDENF) e buscas realizadas em outros banco de dados.

A busca eletrônica foi realizada por pesquisador com experiência no tema dos artigos, ocorreu em abril a junho de 2020 nas bases de dados por meio das diversas combinações das palavras-chave: Primeira combinação: pressure ulcer AND health personnel AND COVID. Segunda Combinação: pressure ulcer AND health personnel AND coronavirus. Terceira combinação: pressure ulcer AND equipment and supplies, hospital AND personal protective equipament. Quarta Combinação: coronavirus AND skin. Quinta Combinação: N95 mask AND occupational. O recurso utilizado na pesquisa foi a expressão do "termo exato". Para cruzar os termos usou-se o operador lógico booleano "and" com o intuito de obter o maior número de artigos que respondam à questão norteadora.

Os critérios de inclusão foram adotados os seguintes: textos disponíveis na íntegra, nos idiomas português, inglês ou espanhol, entre os anos de 2000 a 2020. Estudos voltados para pacientes (adultos ou neonatos) ou que não apresentavam medidas preventivas foram excluídos.

Para extração dos dados utilizou-se os seguintes dados: identificação dos artigos (autor, título e ano de publicação), objetivo, tipo de estudo e resultados principais. Com o processo de seleção dos artigos, resultou-se num total de 14 publicações.

Um fluxograma foi elaborado para identificação e seleção dos artigos seguindo as estratégias de busca e critérios de inclusão e exclusão (Figura 1). 
Registros identificados por meio de pesquisa no banco de dados $(n=410)$

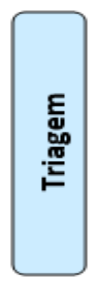

Registros após duplicação removida $(n=315)$
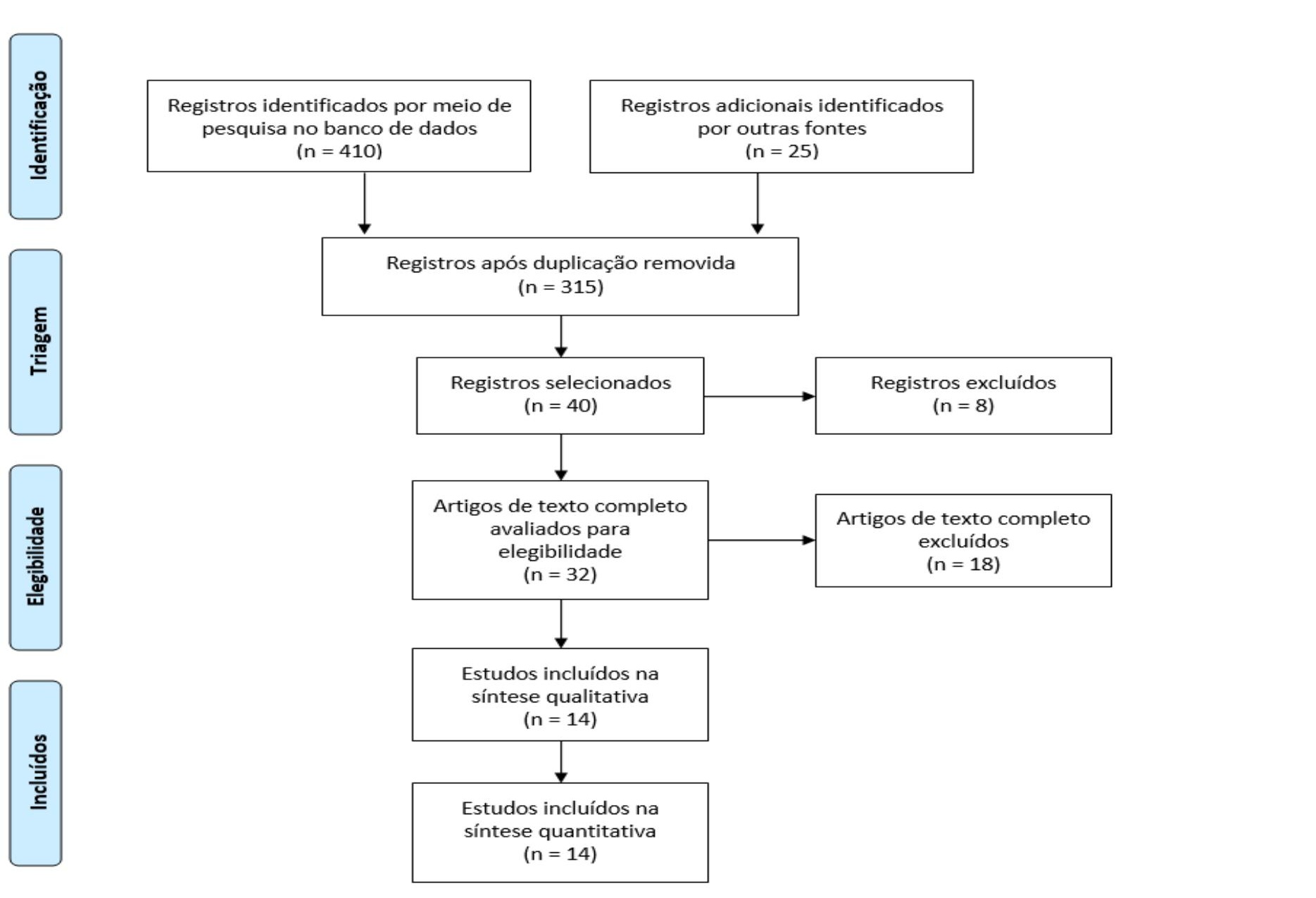

Estudos incluídos na síntese qualitativa $(n=14)$

Estudos incluídos na síntese quantitativa ( $n=14)$

Figura 1 - Fluxograma da seleção dos artigos, segundo o Preferred Reporting Items for Systematic Reviews and Meta Analyses (PRISMA). Belo Horizonte (MG), Brasil, 2020

\section{RESULTADOS}

Do total de 14 artigos, duas são publicações brasileiras sendo uma de Brasília $^{(4)}$ e outra de Rio Grande do Norte ${ }^{(9)}$ um de Porto/ Portugal ${ }^{(10)}$, um estudo da República de Cingapura ${ }^{(11)}$, um do Reino Unido $^{(12)}$, quatro da China ${ }^{(5,13,14,15)}$, um da
Registros adicionais identificados por outras fontes $(n=25)$
Bulgária ${ }^{(16)}$, dois dos Estados Unidos da América ${ }^{(17,18)}$, um do Reino do Bahrein ${ }^{(19)}$ e um em Israel ${ }^{(20)}$. O Quadro 1 apresenta dados de cada estudo e as variáveis analisadas.

Quadro 1. Distribuição dos estudos selecionados. Belo Horizonte (MG), Brasil, 2020

\begin{tabular}{|l|l|l|l|}
\hline$N^{\circ}$ & $\begin{array}{l}\text { Autor - Mês/ Ano de } \\
\text { publicação - Tipo de } \\
\text { Estudo }\end{array}$ & Título & Objetivo \\
\hline
\end{tabular}




\begin{tabular}{|c|c|c|c|c|}
\hline & $\begin{array}{l}\text { Ramalho AO, Freitas } \\
\text { PSS , Nogueira PC }{ }^{(1)}- \\
\text { Janeiro/2020 - Editorial }\end{array}$ & 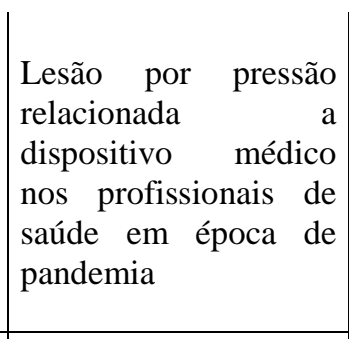 & $\begin{array}{l}\text { Comentar sobre o surgimento } \\
\text { de lesões por pressão } \\
\text { relacionadas a dispositivos } \\
\text { médicos nos profissionais de } \\
\text { saúde devido o uso de } \\
\text { equipamentos de proteção } \\
\text { individual e apresentar } \\
\text { medidas de prevenção }\end{array}$ & \begin{tabular}{|l} 
É fundamental que o \\
autocuidado impere nesse \\
momento de pandemia, pois é \\
necessário que os \\
profissionais estejam com sua \\
saúde preservada para \\
colaborarem com um cuidado \\
efetivo para a sociedade
\end{tabular} \\
\hline & $\begin{array}{l}\text { National } \\
\text { Pressure Injury Advisory } \\
\text { Panel (NPIAP) (2) } \\
\text { Abril/2020 } \\
\text { Recomendação }\end{array}$ & $\begin{array}{l}\text { NPIAP releases } \\
\text { position statements on } \\
\text { N95 mask injuries }\end{array}$ & $\begin{array}{l}\text { analisar as evidências } \\
\text { atuais sobre a prevenção de } \\
\text { lesões por pressão, bem como } \\
\text { os padrões de segurança } \\
\text { atuais e pesquisas sobre EPI }\end{array}$ & $\begin{array}{l}\text { O uso de produtos que evitem } \\
\text { o cisalhamento, a umidade e } \\
\text { a fricção podem ser utilizados } \\
\text { se mantiver a eficácia da } \\
\text { máscara N95. }\end{array}$ \\
\hline & \begin{tabular}{llr} 
Paulo Jorge & \multicolumn{2}{c}{ Pereira } \\
Alves et al & (3) & - \\
Março/2020 & & - \\
Recomendação & &
\end{tabular} & $\begin{array}{l}\text { Recomendação } \\
\text { PREPI/COVID19: } \\
\text { Prevenção de lesões } \\
\text { cutâneas causadas } \\
\text { pelos equipamentos de } \\
\text { proteção individual } \\
\text { (Máscaras faciais, } \\
\text { respiradores, viseiras } \\
\text { e óculos de proteção) }\end{array}$ & $\begin{array}{l}\text { Comentar sobre o surgimento } \\
\text { de lesões por pressão } \\
\text { relacionadas a dispositivos } \\
\text { médicos nos profissionais de } \\
\text { saúde devido o uso de } \\
\text { equipamentos de proteção } \\
\text { individual e apresentar } \\
\text { medidas de prevenção }\end{array}$ & $\begin{array}{l}\text { Usar creme hidratante e } \\
\text { protetor de barreira; Usar } \\
\text { curativo profilático como } \\
\text { interface entre a pele e o EPI } \\
\text { (em zonas de friçcão, pressão } \\
\text { ou adesão; atentar para uso } \\
\text { adequado do EPI respeitando } \\
\text { a anatomia do rosto. }\end{array}$ \\
\hline & $\begin{array}{lrr}\text { Núcleo de Estudos } & \text { e } \\
\text { Pesquisa } & \text { em } \\
\text { Dermatologia } & & \text { e } \\
\text { Estomaterapia } & & \\
\text { (NEPeDE) } & \text { (4) } & - \\
\text { Março/2020 } & & - \\
\text { Recomendação } & & \end{array}$ & $\begin{array}{l}\text { Lesão por máscara de } \\
\text { proteção respiratória } \\
\text { (respirador } \\
\text { particulado - N95 ou } \\
\text { equivalente) }\end{array}$ & $\begin{array}{l}\text { Comentar sobre o surgimento } \\
\text { de lesões por pressão } \\
\text { relacionadas a dispositivos } \\
\text { médicos nos profissionais de } \\
\text { saúde devido o uso de } \\
\text { equipamentos de proteção } \\
\text { individual e apresentar } \\
\text { medidas de prevenção }\end{array}$ & $\begin{array}{l}\text { É essencial que os serviços } \\
\text { promovam as orientações } \\
\text { necessárias e preocupem-se } \\
\text { com a segurança de todos os } \\
\text { profissionais, sendo a LPP } \\
\text { relacionada a dispositivos } \\
\text { médicos um indicador de } \\
\text { qualidade nos serviços de } \\
\text { saúde }\end{array}$ \\
\hline & $\begin{array}{l}\text { Razvigor } \quad \text { Darlenski, } \\
\text { Nikolai Tsankov (5)_- } \\
\text { Março/2020 - Relato de } \\
\text { caso }\end{array}$ & $\begin{array}{l}\text { Covid-19 pandemic } \\
\text { and the skin - What } \\
\text { should dermatologists } \\
\text { know? }\end{array}$ & $\begin{array}{l}\text { apresentar as lesões de pele } \\
\text { decorrente a medidas de } \\
\text { prevenção para COVID } 19\end{array}$ & $\begin{array}{l}\text { Alterações na pele com uso } \\
\text { da máscara N95: acne, } \\
\text { prurido facial, e mesmo } \\
\text { dermatite. Locais da pele } \\
\text { mais comuns foram: a ponte } \\
\text { nasal (devido ao óculos de } \\
\text { proteção), bochechas (devido } \\
\text { ao uso da máscra N95), testa } \\
\text { (devido aos óculos de } \\
\text { proteção) e mãos (devido à } \\
\text { higienização de mãos } \\
\text { excessivamente). }\end{array}$ \\
\hline & $\begin{array}{l}\text { Elston DM } \stackrel{(6)}{ }- \\
\text { Março/2020 } \\
\text { editor }\end{array}$ & $\begin{array}{l}\text { Occupational skin } \\
\text { disease among health } \\
\text { care } \\
\text { the workers during } \\
\text { (COVID-19) epidemic }\end{array}$ & $\begin{array}{l}\text { orientar sobre as lesões } \\
\text { decorrente de equipamentos } \\
\text { de proteção individual } \\
\text { durante pandemia COVID } 19\end{array}$ & $\begin{array}{l}\text { A prevalência de doenças da } \\
\text { pele relacionada ao } \\
\text { equipamento de proteção é } \\
\text { alta e intervenções simples, } \\
\text { incluindo o uso de filmes de } \\
\text { barreira adesiva antes de } \\
\text { vestir o equipamento de } \\
\text { proteção, podem ajudar a } \\
\text { preservar a força de trabalho } \\
\text { vital para o atendimento de }\end{array}$ \\
\hline
\end{tabular}




\begin{tabular}{|c|c|c|c|c|}
\hline & & & & pacientes com a doença. \\
\hline 7 & $\begin{array}{l}\text { Jiajia Lan et al }{ }^{(7)}- \\
\text { Março/2020 }- \text { Coorte } \\
\text { retrospectivo }\end{array}$ & $\begin{array}{l}\text { Skin damage among } \\
\text { health care workers } \\
\text { managing coronavirus } \\
\text { disease-2019 }\end{array}$ & $\begin{array}{l}\text { estimar a prevalência, } \\
\text { características clínicas e } \\
\text { fatores de risco desse dano } \\
\text { cutâneo entre eles }\end{array}$ & $\begin{array}{l}\text { dispositivos médicos por } \\
\text { mais de } 6 \text { horas apresentaram } \\
\text { maiores riscos de danos à } \\
\text { pele em áreas do nariz e } \\
\text { bochechas, enquanto um } \\
\text { tempo maior de uso de um } \\
\text { protetor facial não foi um } \\
\text { fator de risco significativo } \\
\text { para causar danos à pele na } \\
\text { testa. A higiene das mãos } \\
\text { mais frequente (> } 10 \text { vezes ao } \\
\text { dia) pode aumentar o risco de } \\
\text { lesões na pele das mãos, em } \\
\text { vez de um tempo mais longo } \\
\text { de uso de luvas. }\end{array}$ \\
\hline 8 & $\begin{array}{l}\text { Foo } r \text { CC, Goon } \\
\text { AT, Leow YH, Goh CL. } \\
(8)-\text { Outubro/2006 - } \\
\text { Coorte retrospectivo }\end{array}$ & $\begin{array}{l}\text { Adverse skin reactions } \\
\text { to personal protective } \\
\text { equipment against } \\
\text { severeracute } \\
\text { respiratory syndrome- } \\
\text {-a descriptive study in } \\
\text { Singapore. }\end{array}$ & $\begin{array}{l}\text { estudar a prevalência de } \\
\text { reações adversas da pele aos } \\
\text { EPIs entre os profissionais de } \\
\text { saúde de Cingapura durante o } \\
\text { surto de SARS }\end{array}$ & $\begin{array}{l}\text { Principais alterações na pele } \\
\text { identificados foram: com uso } \\
\text { de máscaras N95 - acne } \\
(59,6 \%), \text { coceira facial } \\
(51,4 \%) \text { e erupção cutânea } \\
(35,8 \%) \text {; com uso de luvas - } \\
64 \quad(21,4 \%) \text { dos } \\
299 \text { pele seca }(73,4 \%), \\
\text { coceira }(56,3 \%) \text { e erupção } \\
\text { cutânea }(37,5 \%) \text { O uso de } \\
\text { EPI está associado a altas } \\
\text { taxas de reações adversas } \\
\text { na pele. }\end{array}$ \\
\hline 9 & $\begin{array}{l}\text { Gefen A, Ousey } K^{(9)}- \\
\text { Maio/2020 - Consenso }\end{array}$ & 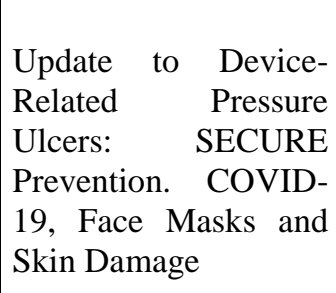 & $\begin{array}{l}\text { fornecer aos profissionais da } \\
\text { linha da de frente à } \\
\text { assistência ao covid-19 } \\
\text { estratégias simples para } \\
\text { evitar danos à pele devido } \\
\text { uso de equipamentos de } \\
\text { proteção individual }\end{array}$ & \begin{tabular}{|lrr} 
curativos & \multicolumn{2}{c}{ profiláticos } \\
aplicados como protetores da \\
pele sob EPI podem ser \\
muito diferentes com os \\
vários tipos disponíveis de \\
máscaras
\end{tabular} \\
\hline 10 & \begin{tabular}{|lll} 
Jiang Q et & al & (10) \\
Junho/2020 & - & Estudo \\
transversal & &
\end{tabular} & $\begin{array}{l}\text { The Prevalence, } \\
\text { Characteristics, and } \\
\text { Prevention Status of } \\
\text { Skin Injury Caused by } \\
\text { Personal Protective } \\
\text { Equipment Among } \\
\text { Medical Staff in } \\
\text { Fighting COVID-19: } \\
\text { A Multicenter, Cross- } \\
\text { Sectional Study }\end{array}$ & $\begin{array}{l}\text { Investigar a prevalência, } \\
\text { características e status } \\
\text { preventivos de lesões de pele } \\
\text { causadas por EPI na equipe } \\
\text { médica }\end{array}$ & $\begin{array}{l}\text { Prevalência de } 42,8 \% \text { de } \\
\text { lesões em pele de } \\
\text { profissionais, com três tipos } \\
\text { de lesões por pressão: } \\
\text { relacionada a dispositivo; } \\
\text { danos à pele associados à } \\
\text { umidade e; lacrimejamento }\end{array}$ \\
\hline 11 & $\begin{array}{l}\text { Smart H et al }{ }^{(11)}- \\
\text { Junho/2020 }- \text { Série de } \\
\text { casos }\end{array}$ & $\begin{array}{l}\text { Preventing Facial } \\
\text { Pressure Injury for }\end{array}$ & $\begin{array}{l}\text { Determinar se um curativo à } \\
\text { base de silicone usado sob } \\
\text { uma máscara N95 é uma }\end{array}$ & $\begin{array}{l}\text { O teste de desgaste de } 4 \text { horas } \\
\text { confirmou que a proteção } \\
\text { facial bem ajustada não }\end{array}$ \\
\hline
\end{tabular}




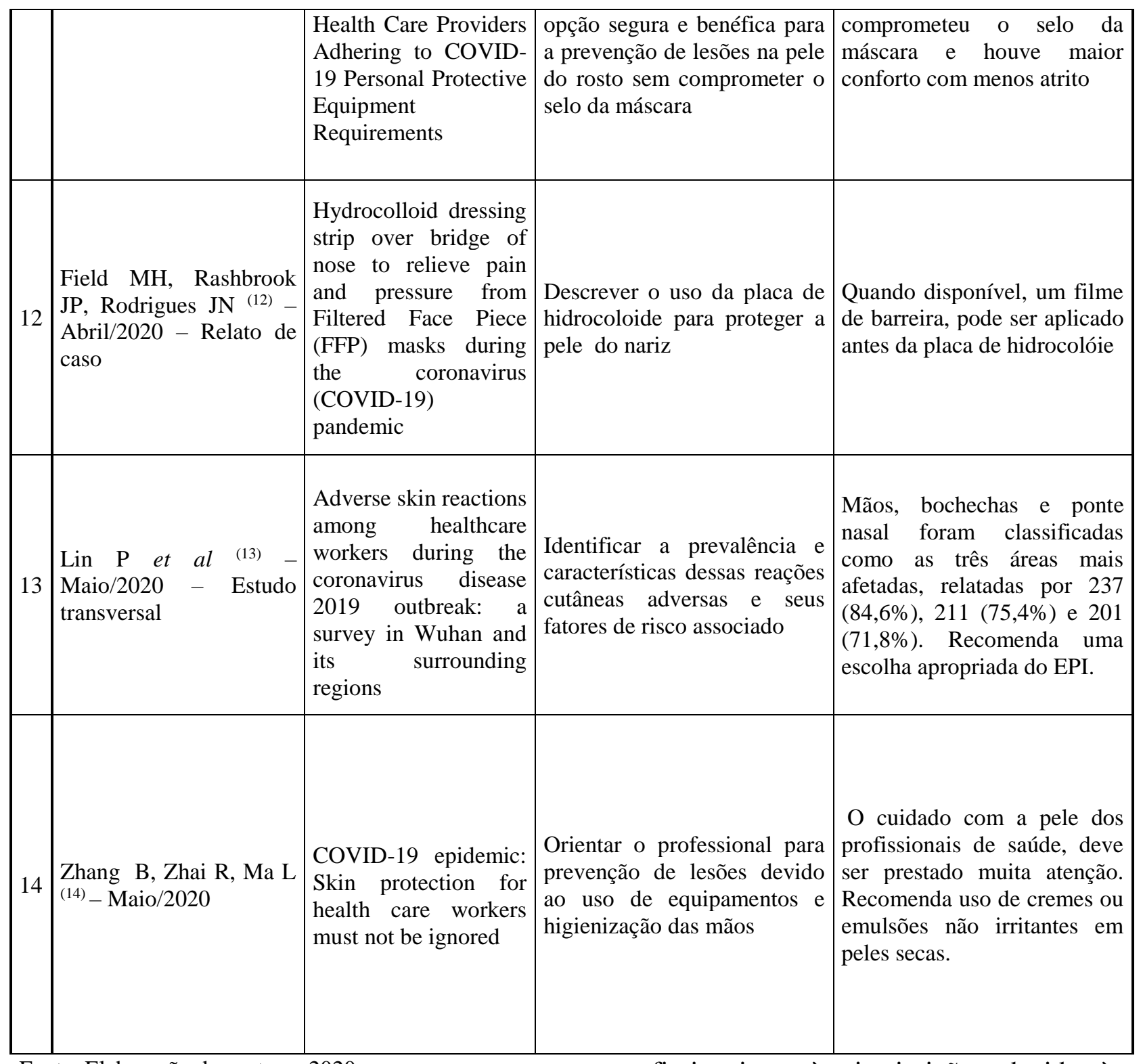

profissionais e às instituições devido às

\section{DIISCUSSÃO}

Elston (17) descreve diversos episódios, pandemias ou períodos de guerra, como exemplos na história sobre as lesões de pele em profissionais gerando redução da força de trabalho. Apesar de histórico, não nos preparamos para reduzir os danos aos lesões desenvolvidas por EPI em profissionais da saúde. Foo em $2003^{(11)}$, após o surto de SARS, já havia descrito que possivelmente teríamos outros surtos, talvez esses autores não imaginariam uma pandemia por COVID-19, tal como estamos vivendo neste momento, causando tantos estragos na saúde das pessoas e na área 
financeira em todos os países. Estes autores afirmaram a necessidade em conhecer e reconhecer a existência das lesões nos profissionais e nos prepararmos para os próximos eventos ${ }^{(11)}$.

Enfim, não nos preparamos $\mathrm{e}$ continuamos com poucas ações e poucos estudos sobre medidas preventivas voltadas para o público de profissionais, as recomendações das instituições e associações profissionais relatam as mesmas medidas voltadas para o paciente em uso de máscara de ventilação não invasiva (VNI), visto que se apresenta como mesmo mecanismo de ação, ou seja, força mecânica causada por pressão e cisalhamento ${ }^{(18)}$. Porém os EPI não podem permitir vazamentos ou uso de produtos que alterem a proteção completa do profissional (21) assim o uso de curativos protetores não pode alterar a segurança do EPI.

Alves et al (10), ressaltam a importância em proteger o profissional, pois as lesões ou alterações na pele do profissional de saúde são portas de entrada para outras infecções virais, fúngicas ou bacterianas adquiridas no ambiente hospitalar, o que sugere microrganismos com maior resistência aos tratamentos atuais.

Os estudos apontam para grandes possibilidades de os profissionais desenvolverem lesão por pressão relacionada à dispositivo médico, principalmente pelo uso prolongado da N95, Elston ${ }^{(17)}$ relata prevalência de $97 \%$ de alterações na pele de profissionais assistenciais nos casos de COVID-19.

Não há na literatura até o momento estudos com boa evidência para realizar uma análise de informações mais precisas, visto que os estudos encontrados relatam apenas documentos institucionais ou editorial, poucos são os estudos com pesquisa de campo, sendo um realizado em Cingapura após o surto de SRAS em 2003, avaliando as alterações na pele dos profissionais com uso de EPI's ${ }^{(11)}$, trata-se de estudo realizado há mais de quinze anos e, no entanto, percebemos com a pandemia COVID-19, que ainda é um tema atual, porém pouco descrito na literatura.

Os locais da pele mais acometidos, descritos por estes estudos, foram: a área do nariz, bochechas e testa em menor proporção ${ }^{(13)}$. Estudo de Jiang ${ }^{(5)}$ relata além de lesões por pressão relacionada a dispositivos médicos, lesões por umidade e até danos a pele devido lacrimejamento. Já o estudo de Darlenski e Tsancov ${ }^{(16)}$ relatam dermatite em mãos devido à higienização das mãos excessivamente, sendo esta ação de maior importância na prevenção de infecção por 
COVID-19, esfregar excessivamente as mãos, o uso do álcool em gel também foi descrito como fator para desenvolvimento de alterações na pele.

A máscara N95 foi descrita em todos os estudos como dispositivo médico com maior probabilidade para desenvolvimento da lesão por pressão, Elston ${ }^{(17)}$ relata ainda que, não apenas a máscara, mas os óculos de proteção também contribuem para desenvolver as lesões.

Nos estudos, identificamos relatos do uso de EPI por oito a dez horas direto, pois os profissionais, por medo de se contaminarem, optam por não retirar o equipamento até o fim do plantão, pois o momento da desparamentação, tem sido o momento mais crítico e com maior risco para o profissional.

Sabemos que a ação para desenvolver LPP, ocorre da mesma forma que em pacientes com ventilação não invasiva, então podemos seguir os mesmos três fatores para evitar lesão por pressão, para os profissionais ${ }^{(18)}$, lembrando para atentarmos que estas medidas não podem reduzir a eficácia dos EPI's na proteção contra COVID-19. Identificando a tríade para desenvolver LPP, segue: a) intensidade da pressão e cisalhamento; b) duração da pressão e cisalhamento; c) tolerância da pele do indivíduo. Identificamos nos estudos encontrados, algumas medidas para prevenção de LPP com base nesta tríade.

a) Cuidados com a pele

1) manter a pele limpa com uso de sabonetes com $\mathrm{pH}$ neutros, utilizar cremes hidratantes, atentar para não causar hidratação excessiva ${ }^{(22)}$.

2) Uma alimentação saudável e hidratação ajudam a manter a pele mais resistente e forte ${ }^{(8,23)}$.

3) Uso de creme ou protetores de barreira, podem evitar oleosidade excessiva da pele, reduzindo assim o cisalhamento e desaceleram a transpiração reduzindo a umidade no local de contato com EPI ${ }^{(10,18)}$.

4) Não é recomendado o uso de produtos oleosos, como vaselina ou óleo mineral, pois estes produtos contribuem para $\mathrm{o}$ deslizamento do EPI na pele, causando cisalhamento ${ }^{(18)}$.

b) Minimizar a intensidade da pressão ${ }^{(4)}$

1) Uso de curativos preventivos finos podem contribuir na redução dos riscos de lesão por 
pressão, atentando para que o produto não permita brechas entre o EPI e a pele ${ }^{(24)}$.

2) O curativo deverá ter espessura fina, não ser traumático durante a retirada, absorver a umidade da pele, se adaptar ao rosto, deve garantir sempre que haja vedação entre a pele e o EPI ${ }^{(10)}$.

3) Os produtos recomendados tem sido filme transparente de poliuretano e filme de silicone ${ }^{(25,}$ 26).

4) Uso de hidrocoloide e curativos de espuma, não tem sido recomendado, uma vez que apresentam uma espessura que podem interferir na vedação da máscara N95. Estudos ${ }^{(24)}$ relatam que uso de hidrocoloides aumentam a pressão facial e aumenta o vazamento em máscaras de VNI, podendo assim, quanto ao uso da máscara N95, permitir entradas do vírus da COVID-19 nas frestas entre a pele e a máscara.

c) Reduzir o tempo/ duração da pressão

1) A remoção da máscara durante 15 minutos a cada duas horas. Porém esse período para o profissional de saúde em meio à pandemia COVID-19 pode não ser viável, assim os autores relatam que qualquer momento para descompressão é útil ${ }^{(4,10,18)}$.

2) O profissional deverá atentar para técnica de desparamentação adequada, antes de realizar a descompressão do EPI ${ }^{(27)}$.

\section{CONSIDERAÇÕES FINAIS}

Apesar do conhecimento adquirido de outros surtos que também apresentaram danos a pele e lesões por pressão em profissionais decorrente do uso de equipamentos de proteção, ainda há falta de estudos na literatura sobre as medidas para reduzir a incidência destes eventos em profissionais da saúde, sendo consideradas lesões ocupacionais. Diante dos poucos estudos analisados, para prevenção de lesão por pressão relacionada a dispositivo médico em profissionais durante assistência a pacientes com COVID-19, devemos identificar os tipos de dispositivos que causam a lesão, de forma individual e aplicar as medidas já conhecidas, baseadas em evidências científicas e implantadas a partir de protocolos destinados aos pacientes bem 
como divulgar as informações para as equipes de saúde. A informação ao profissional sobre os riscos e as medidas preventivas é de fato o primeiro passo para a prevenção de lesões por pressão em profissionais de saúde.

\section{REFERÊNCIAS}

1. 1. WHO. Novel Coronavirus - Republic of Korea (ex-China). 2020.

2. Worldometers. Coronavirus statistics 2020 [Available from: https://www.worldometers.info/coronavirus/.

3. Morawska L, Cao J. Airborne transmission of SARS-CoV-2: The world should face the reality. Environ Int. 2020;139:105730.

4. Ramalho A, Freitas P, Nogueira P. Lesão por pressão relacionada a dispositivo médico nos profissionais de saúde em época de pandemia. ESTIMA, Braz J Enterostomal Ther. 2020;18.

5. Jiang Q, Song S, Zhou J, Liu Y, Chen A, Bai Y, et al. The Prevalence, Characteristics, and Prevention Status of Skin Injury Caused by Personal Protective Equipment Among Medical Staff in Fighting COVID-19: A Multicenter, Cross-Sectional Study. Advances in Wound Care. 2020;9(7):357-64.

6. Galetto S, Nascimento E, Hermida PMV, Malfussi LBH. Medical DeviceRelated Pressure Injuries: an integrative literature review. Rev Bras Enferm. 2019;72(2):505-12.
7. Moraes J, Borges E, Lisboa C, Cordeiro D, Rosa E, Rocha N. Conceito e classificação de lesão por pressão: atualização do National Pressure Ulcer Advisory Panel. Revista de Enfermagem do Centro-Oeste Mineiro. 2016;6.

8. Kottner J, Cuddigan J, Carville K, Balzer K, Berlowitz D, Law S, et al. Prevention and treatment of pressure ulcers/injuries: The protocol for the second update of the international Clinical Practice Guideline 2019. J Tissue Viability. 2019;28(2):51-8.

9. NEPeDE. Lesão por máscara de proteção respiratória (respirador particulado - N95 ou equivalente). In: Estomaterapia/UFRN NdEePeDe, editor. Natal (RN)2020.

10. Alves $\mathrm{P}$, Ramos $\mathrm{P}$, Moura A, Malcato E, Mota F, Homem-Silva P, et al. Recomendação PREPI | COVID19 PRevenção de lesões cutâneas causadas pelos Equipamentos de Proteção Individual (Máscaras faciais, respiradores, viseiras e óculos de proteção). Journal of Tissue Healing and Regeneration. 2020.

11. Foo CC, Goon AT, Leow YH, Goh CL. Adverse skin reactions to personal protective equipment against severe acute respiratory syndrome--a descriptive study in Singapore. Contact Dermatitis. 2006;55(5):291-4.

12. Field MH, Rashbrook JP, Rodrigues JN. Hydrocolloid dressing strip over bridge of nose to relieve pain and pressure from Filtered Face Piece (FFP) masks during the coronavirus (COVID-19) pandemic. Ann R Coll Surg Engl. 2020;102(5):394-6.

13. Lan J, Song Z, Miao X, Li H, Li Y, Dong L, et al. Skin damage among health 
care workers managing coronavirus disease2019. Journal of the American Academy of Dermatology. 2020;82(5):1215-6.

14. Lin P, Zhu S, Huang Y, Li L, Tao J, Lei $\mathrm{T}$, et al. Adverse skin reactions among healthcare workers during the coronavirus disease 2019 outbreak: a survey in Wuhan and its surrounding regions. The British journal of dermatology. 2020:10.1111/bjd.19089.

15. Zhang B, Zhai R, Ma L. 2019 novel coronavirus disease epidemic: skin protection for healthcare workers must not be ignored. Journal of the European Academy of Dermatology and Venereology : JEADV. 2020:10.1111/jdv.16573.

16. Darlenski R, Tsankov N. Covid-19 pandemic and the skin - What should dermatologists know? Clinics in Dermatology. 2020.

17. Elston DM. Occupational skin disease among health care workers during the coronavirus (COVID-19) epidemic. J Am Acad Dermatol. 2020;82(5):1085-6.

18. NPIAP. NPIAP posittion statements on preventing injury with N95 masks. Westford, MA (EUA): National Pressure Injury Advisory Panel; 2020.

19. Smart H, Opinion FB, Darwich I, Elnawasany MA, Kodange C. Preventing Facial Pressure Injury for Health Care Providers Adhering to COVID-19 Personal Protective Equipment Requirements. Adv Skin Wound Care. 2020.

20. Gefen A, Ousey K. Update to devicerelated pressure ulcers: SECURE prevention. COVID-19, face masks and skin damage. J Wound Care. 2020;29(5):245-59.
21. Cavalcanti EdO, Kamada I. Medicaldevice-related pressure injury on adults: an integrative review. Texto \& Contexto Enfermagem. 2020;29.

22. Visscher MO, White CC, Jones JM, Cahill T, Jones DC, Pan BS. Face Masks for Noninvasive Ventilation: Fit, Excess Skin Hydration, and Pressure Ulcers. Respir Care. 2015;60(11):1536-47.

23. Munoz N, Posthauer ME, Cereda E, Schols J, Haesler E. The Role of Nutrition for Pressure Injury Prevention and Healing: The 2019 International Clinical Practice Guideline Recommendations. Adv Skin Wound Care. 2020;33(3):123-36.

24. Riquelme MH, Wood VD, Martinez FS, Carmona MF, Pena VA, Wegner AA. [Face protective patches do not reduce facial pressure ulcers in a simulated model of noninvasive ventilation]. Rev Chil Pediatr. 2017;88(3):354-9.

25. Weng MH. The effect of protective treatment in reducing pressure ulcers for non-invasive ventilation patients. Intensive Crit Care Nurs. 2008;24(5):295-9.

26. Ozbudak G, Yesilbalkan OU. Effect of transparent film on the duration of pressure ulcer formation for noninvasive ventilation patients: A randomized controlled trial. Niger J Clin Pract. 2020;23(1):91-7.

27. COFEN. COVID-19: Orientações sobre a colocação e retirada dos equipamentos de proteção individual (EPIs). In: Enfermagem CFd, editor. 2020. p. 18.

Recebido: $2020-06-28$

Aceito: 2020-07-15 